Dicle Tıp Dergisi / Dicle Medical Journal (2017) 44 (2) : 151-158

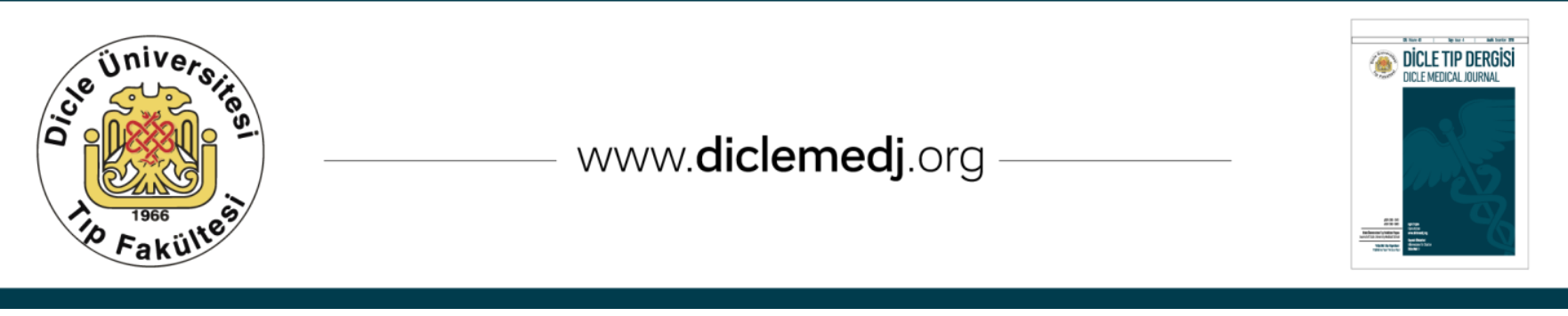

Özgün Araștırma / Original Article

\title{
Kliniğimizde Malignite Rıskı İndeksinın Sınır Değerinin Belirlenmesi
}

\author{
Hakan Guraslan1, Mehmet Baki Şentürk² ${ }^{2}$ Levent Yaşar1 \\ 1 Türkiye1 Bakırköy Dr. Sadi Konuk Eğitim ve Araștırma Hastanesi, Kadın Hastalıkları ve Doğum Kliniği, \\ Zuhuratbaba Mah. No: 11, Bakırköy, İstanbul, Türkiye \\ 2 Zeynep Kamil Kadın Hastalıkları ve Doğum, Çocuk Hastalıkları Hastanesi Eğitim ve araştırma Hastanesi, \\ Op. Dr. Burhanettin Üstünel Caddesi, No:10, 34668, Üsküdar, İstanbul, Türkiye
}

Geliş: 03.07.2016 Revizyon: 14.02.2017 Kabul Tarihi: 20.02.2017

\section{Özet}

Amaç: Epitelyal over kanseri jinekolojik kanserlerden ölüm nedenleri içinde ilk sırada yer alır. Hastalığın tanı anındaki evresi en önemli prognostik faktördür ve erken evre over kanserinde survi belirgin olarak daha iyidir. Bu nedenle adneksiyel kitle ile başvuran bir olgunun erken dönemde değerlendirilmesi önem kazanmaktadır. Diğer yandan benign kitlelerin gereksiz cerrahisi morbidite ve mortalite riski yanında artan bir maliyet nedenidir. Adneksiyal kitlelerin operasyon öncesi değerlendirilmesinde malignite indeksi risk skoru kullanışlı olmasına rağmen genel populasyona indirgemek zordur ve farklı populasyonlar için farklı sınır değerler önerilmektedir. Bu retrospektif çalışmada biz kendi kliniğimizdeki olgular için uygun olabilecek sınır değerini araştırdık.

Yöntemler: Adneksiyal kitle nedeniyle kliniğimizde opere edilen 235 olgu retrospektif olarak incelendi. Olguların kitle boyutu, lokalizasyonu, asit varlığı, kitlenin morfolojik özellikleri ve menopoz durumuna göre malignite indeksi risk skoru hesaplandı. Risk skoru için kesme değeri belirlemede tanı tarama testleri (duyarlılık, özgüllük, pozitif ve negatif belirleyici değer) ve ROC Curve analizi kullanıldı. Ayrıca sınır değer 100, 150 ve 200 için duyarlılık, özgüllük, pozitif ve negatif belirleyici değerler Yates' Continuity Correction Test ile araştırıldı. Anlamlılık $p<0.01$ ve $p<0.05$ düzeylerinde değerlendirildi.

Bulgular: Malignite indeksi risk skoru 100 kesme değeri için; duyarlılık \%80, özgüllük \%81,4, pozitif belirleyici değeri $\% 33,9$ ve negatif belirleyici değeri \%97,2'dir. Elde edilen ROC eğrisinde altta kalan alan \%84,1 standart hatası \%5,0 olarak saptanmıştır. Sınır değeri olarak 100 için malign sonuçların görülme riski 17.5 kat, 150 için 15.7 kat ve 200 için 13.5 kat daha fazladır.

Sonuç: Bu çalışmadaki populasyon için en iyi malignite indeksi risk skoru sınır değeri 100 olarak bulunmuştur. Malignite indeksi risk skoru için herhangi bir sınır değeri tüm popülasyonlara genellemek zor görünmektedir ve yeni farklı populasyonları içeren çalışmalara ihtiyaç vardır.

Anahtar kelimeler: Epitelyal Over Kanser, Morbidite, Mortalite

DOI: $10.5798 /$ dicletip.319736

Yazışma Adresi / Correspondence: Mehmet B. Şentürk, Zeynep Kamil Kadın Hastalıkları ve Doğum, Çocuk Hastalıkları Hastanesi Eğitim ve araştırma Hastanesi, Op. Dr. Burhanettin Üstünel caddesi, No 10, 34668, Üsküdar, İstanbul, Türkiye 7176 e-mail: dr.baki77@gmail.com 


\title{
Calculation Of Risk Of Malignancy Index In Our Clinic
}

\begin{abstract}
Objective: Epithelial ovarian cancer is the first cause of death among gynecologic cancers. The most important prognostic factor is the stage of disease and the overall survival is better in early stage. Hence the evaluation of the patient with adnexal mass is important. On the other hand unnecessary surgery can increase morbidity, mortality and the unnecessary cost. Although malignity index risk score is a useful tool for preoperative evaluating of adnexal masses, it is difficult to use and different cut off values are recommended for different populations. In this retrospective analysis, we investigate proper cut off values for our patients who underwent surgery for adnexal masses.

Methods: We evaluated the outcomes of 235 patients underwent surgery for adnexal masses retrospectively. Malignity risk score was calculated according to the dimension of the masses, their localization, presence of ascites, menopause status and CA 12.5 level. For determining the cut off level of RMI, ROC curve analysis was used. Sensitivity, specificity, positive and negative predictive value also evaluated for cut-off value of 100, 150 and 200 . A p value was statistically accepted meaningful when $\mathrm{p}<0.01$ and $\mathrm{p}<0.05$.

Results: For the cut-off value of 100 , sensitivity was $80 \%$, specificity was $81.4 \%$, positive predictive value was $33.9 \%$ and negative predictive value was $97.2 \%$. in the ROC curve the underlying area $84.1 \%$ of the standard error was determined as 5.0\%. The risk of having a malignant outcome of 100 as a border value is 17.5 fold, 15.7 fold for 150 and 13.5 fold for 200 .

Conclusion: In this study, the best cut-off value for determining malign adnexal masses was 100 . It seems to be difficult to generalized any cut-off value of RMI. There is need for large study in the different populations to obtain a consensus for cut-off value of RMI.
\end{abstract}

Keywords: Epithelial Ovarian Cancer, Morbidity, Mortality

\section{GİRIŞ}

Epitelyal over kanseri yaygın bir jinekolojik kanser olup yüksek mortaliteye sahiptir ${ }^{1}$. Kemoterapideki gelişmelere rağmen mortalite riski hala yüksektir ${ }^{1}$. Bu hastalığın çoğunlukla geç evrede saptanmasına bağlıdır. Semptomlar nonspesifik olduğundan erken evrede tanı koymak zor olabilir ${ }^{1}$. Olguların \%60'ı evre 3 ya da 4 de başvurmaktadır ve ortalama survi $\% 27$ civarındadır $^{2}$. Bu nedenle adneksiyal kitle ile başvuran bir hastada over kanserini tahmin etme ve hastayı cerrahiye refere etme oldukça önem kazanmaktadır. Öte yandan kanser olmadığı halde gereksiz cerrahi yapılan olgulardaki morbidite, mortalite ve maliyeti de göz önünde bulundurmak gereklidir. Böylece adneksiyal kitlenin malign benign ayırımında süregelen araştırmalar ile birtakım teknikler önerilmiş fakat genellenebilecek yüksek duyarlılığa sahip bir teknik bulunmamaktadır. 1990 da Jakops ve arkadaşlarl ${ }^{3}$ malignite riskini hesaplayan malignite indeksi risk skoru (risk of malignancy index, RMI) sistemini geliştirdiler. $\mathrm{Bu}$ sistem ultrasonografik kriterler, menopoz durumu ve CA 12.5 düzeyini hesaplanmasından oluşmaktaydl ${ }^{3}$. Bu kriterlerin kombine edilmesi tek tek her bir kritere göre ovarian kanseri saptamada daha effektif idi $^{3}$. Bu skorlama sisteminde sınır değer 200 alındığında \%85 duyarlılık ve \%97 özgüllük ile malign benign ayırımını yapabilmekteydi ${ }^{3}$. RMI ile ilgili, özellikle de sınır değeri ile ilgili çalışmalar sürerken, mortalite üzerine olumlu net bir etkisinin olmadığı görülmüştür ${ }^{4-10}$. Çünkü RMI testinin genele uygulanmasinda zorluklar olmakta ve her populasyon için farklı sınır değerler görülebilmektedir ${ }^{2}$.

$\mathrm{Bu}$ çalışmada kendi kliniğimizde tamamı cerrahi yapılmış adneksiyal kitlelerin patoloji sonuçları ile RMI skorları arasındaki ilişkiyi retrospektif olarak inceledik. Ayrica incelediğimiz olgular için malign benign 
ayırımında uygun olabilecek bir sınır değer de araştırdık.

\section{YÖNTEMLER}

Çalışma Bakırköy Dr Sadi konuk Eğitim ve Araştırma Hastanesi Kadın Doğum Kliniğinde 2010 ile 2016 tarihleri arasinda adneksiyal kitle nedeniyle opere olmuș 235 olgunun dosya bilgilerinin retrospektif incelenmesi ile yapıldı. Opere edilen tüm hastalardan bilgilendirilmiş onam alındı. Çalışma Zeynep Kamil Eğitim ve Araştırma Hastanesi etik kurul tarafından kabul edildi (No:35). Dosya bilgilerinden hastaların yaş, menopozal durum, CA 12.5 değeri, asit varlığı, kitlenin bilateral ya da unilateral olup olmadığı, asit ve metastaz varlığı, multilokülasyon ve solid alan varlığı ile hesaplanmış RMI değerlerine ulaşıldı.

RMI hesaplanırken Jacobs ve ark. nın önerdiği menapoz skoru (M) x ultrasonografi skoru (U) x CA-125 değeri çarpımından elde edilen sonuçlar değerlendirildi ${ }^{3}$. En az 1 yıl amenoresi olan hastalar menopozda kabul edildi. Menopoz skoru hesaplanırken premenopoz hastalara 1 puan, menopozdaki hastalara 3 puan verildi. Ultrasonografik incelemede bilateralite, solid alan varlığı, asit, metastaz düşündüren bulgu ve multilokülasyon dahil beş özelliğe bakıldı. Herbiri için var olmasına göre bir puan verildi. beş parametrenin puanı toplandı. Ultrasonografi skoru hiçbirini taşımayan için 0 , toplam 1 puan için 1 ve 2 veya daha fazla toplam puan alması halinde 3 olarak hesaplandl.

Histopatolojik tanı, sonuçların yorumlanmasında altın standart kabul edildi. Nihai patoloji sonuçları patoloji datalarından bulunarak RMI ve diğer özellikler ile patoloji sonuçları arasındaki ilişki araştırıldı.

Patoloji sonuçları benign ve malign şeklinde iki gruba ayrılarak, yaş, kitle boyutu, CA 12.5 değeri, RMI değeri, menapozal durum, bilateralite, multilokülasyon, solid alan, asit varlığ karşılaştırıldı. Yine benign malign ayırımında
RMI değeri için ROC curve değeri araștırıldı. Bununla beraber RMI sınır değeri 100, 150 ve 200 alınarak bu değerlerde duyarlılık, özgüllük, negatif ve pozitif belirleyici değer araştırıldı.

İstatistiksel analizler için NCSS (Number Cruncher Statistical System) 2007 (Kaysville, Utah, USA) programı kullanıldı. İki grup arasında yaş, menopozal durum, CA 12.5 değeri, RMI sonucu ile kitlenin özellikleri Mann Whitney U Test, Yates' Continuity Correction Test, Fisher's Exact Test ile karşılaştırıldı. Belirlenmiş sınır RMI değerlerinde $(100,150$, 200) benign ve malign olgu sayısı Fisher Exact test ile karşılaştırıldı. RMI için cut off belirlemede tanı tarama testleri (duyarlılık, özgüllük, pozitif ve negatif belirleyici değer) ve ROC Curve analizi kullanıldı. Anlamlılı $\mathrm{p}<0.01$ ve $p<0.05$ düzeylerinde değerlendirildi.

\section{SONUCLLAR}

Çalışmamı 20.04.2014 ile 15.06.2016 tarihleri arasında Bakırköy Dr. Sadi Konuk Eğitim ve Araştırma Hastanesi Kadın Hastalıkları ve Doğum Kliniği'nde opere edilen 235 olgu ile yapıldı. Olguların yaşları 16 ile 88 arasında değişmekte olup, ortalama $45.6 \pm 14.4$ yıldı. Toplam 235 adneksiyal kitlenin yaklaşı $\% 89$ 'u benign $(n=220)$, \%11'i malign $(n=25)$ patolojiye sahipti (Tablo 1).

En sık saptanan patoloji seröz kistadenom, en sık nonneoplastik patolojik sonuçlar ise endometrioma $(\% 14,9)$ ve dermoid kist $(\% 14,5)$ idi. Malign tümörlerin 4 tanesi metastatik, 2 tanesi germ hücreli tümör iken kalan 19 malign kitle primer epitelyal over tümörü idi (Tablo 2).

Benign ve malign olgular karşılaştırıldığında, CA 12.5 değeri, kitle boyutu, kitlenin septalı olma, solid alan içerme ve metastatik olma oranı malign olgularda belirgin olarak daha yüksekti $(p<0.01)$. RMI değeri yine malign kitlesi olan hastalarda daha yüksekken $(p<0.01)$, ileri yaş, menopozal durum ve bilateral kitle varlığı daha yüksek oranda olsa 
da malignite ile istatistiksel olarak ilişkili bulunmadı (Tablo 3). Benzer şekilde RMİ bileșenlerinin 100 kesme değeri ile ilişkisi ayrı ayrı değerlendirildiğinde yaş ve menopozal durum dışında tüm malignite kriterleri yüksek RMİ değeri ile anlamlı olarak ilișkiliydi $(p=0.001)$. RMI düzeyi 100 ve üzeri olan olgularda multilokülasyon görülme oranı yaklaşık 4 kat (\%95 Cl: 2.1-8.1), solid alan görülme oranı 9 kat (\%95 Cl: 4.4-18.6), asit görülme oranı ise 23 kat (\%95 Cl: 2.8-195.9) daha fazlaydı.

Tablo 1. Tanımlayıcı Özelliklerin Dağılımı

\begin{tabular}{|c|c|c|c|}
\hline Yaş (yil) & Min-Mak (Medyan) Ort \pm Ss & $16-88(46)$ & $45,6 \pm 14,4$ \\
\hline Kitle boyutu $(\mathrm{cm})$ & Min-Mak (Medyan) Ort $\pm S s$ & $1-30(6)$ & $7,3 \pm 4,5$ \\
\hline Ca 125 & Min-Mak (Medyan) Ort \pm Ss & $3-5172(18)$ & $114 \pm 490$ \\
\hline RMi & Min-Mak (Medyan) Ort $\pm S s$ & $3-24201(36)$ & $558 \pm 2553$ \\
\hline Menapozal durum & n (\%) & 95 & 40,4 \\
\hline Bilateralite & n (\%) & 40 & 17,0 \\
\hline Multilokülasyon & $\mathrm{n}(\%)$ & 49 & 20,9 \\
\hline Solid alan & $\mathrm{n}(\%)$ & 44 & 18,7 \\
\hline Asit & $\mathrm{n}(\%)$ & 8 & 3,4 \\
\hline Metastaz & $\mathrm{n}(\%)$ & 5 & 2,1 \\
\hline \multirow{2}{*}{ Patoloji sonucu } & Benign $n(\%)$ & 210 & 89,4 \\
\hline & Malign n (\%) & 25 & 10,6 \\
\hline
\end{tabular}

Patoloji sonucu ile RMİ düzeyinin 100, 150 ve 200 kesme değeri arasında istatistiksel olarak anlamlı ilişki saptanmıştır $(\mathrm{p}<0.01)$ (Tablo 4). RMİ düzeyi 100 ve daha yüksek olan olgularda malign sonuçların görülme riski 17.5 kat (\%95 CI: 6.2-49.6), 150 kesme değeri için 15.7 kat (\%95 CI: 6.2-40.2) ve 200 kesme değeri için 13.5 kat (\%95 CI: 5.4-33.8) daha fazladır.

RMI sınır değeri 100, 150 ve 200 için duyarlılık, özgüllük, negatif ve pozitif belirleyici değerler tablo 5 görülmektedir.

ROC analizinde ovaryan kitlelerin malignbenign ayrımında en uygun duyarlılık ve özgüllüğe sahip RMİ kesme değeri 100 olarak belirlendi (Duyarlılık \%80,0, özgüllük \%81,4, pozitif belirleyici değeri 33.9 ve negatif belirleyici değeri 97.2). Elde edilen ROC eğrisinde altta kalan alan 0.841 (95\% CI: 0.743$0.939, \mathrm{p}=0.001)$ standart hata $\% 5,0$ olarak saptanmıştır (Şekil 1).

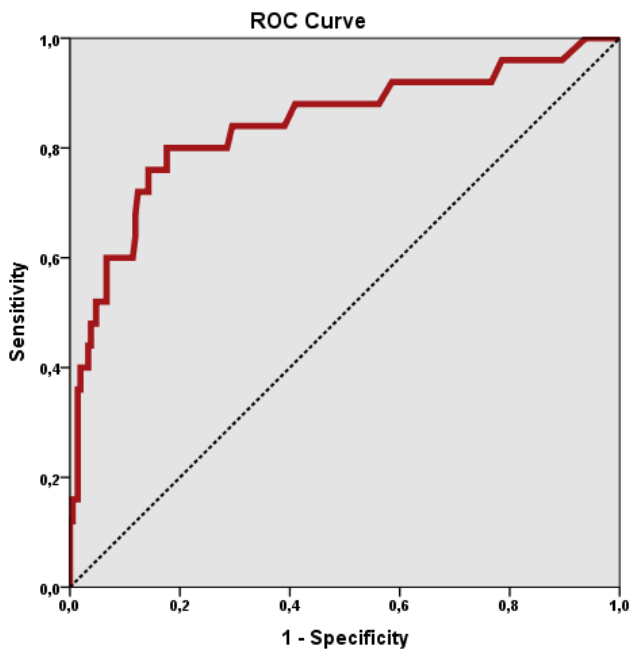

Şekil 1: RMİ düzeyine ilişkin ROC eğrisi 


\begin{tabular}{lcc} 
Tablo 2. Patoloji sonuçlarının dağılımı & \\
\hline Patoloji & $\mathrm{n}$ & $\%$ \\
\hline Seröz & 11 & 4,7 \\
Müsinöz & 2 & 0,9 \\
Berrak hücreli & 2 & 0,9 \\
Borderline & 4 & 1,7 \\
Germ hücreli & 2 & 0,9 \\
Metastatik & 4 & 1,8 \\
Seröz & 52 & 22,1 \\
Müsinöz & 13 & 5,5 \\
Fibrotekom, & 11 & 4,7 \\
Dermoid kist & 34 & 14,5 \\
Endometrioma & 35 & 14,9 \\
Diğer & 65 & 27,7 \\
\hline Total & 235 & 100,0
\end{tabular}

Diğer: İnflamasyon, folikul kisti, korpus hemorajikum, korpus luteum, inkluzyon kisti, paratubal kist

\section{TARTIŞMA}

Çalışmamızın sonuçlarına göre adneksiyal kitlelerin benign malign ayırımında RMI değeri bu çalışmadaki örneklem için 100 sınır değerinde kullanışlı görünmektedir $(\mathrm{p}<0.01)$.

Ovarian kanser abdominal ağrı, karın şişliği, kitle, sık idrara çıkma, anormal vaginal kanama gibi farklı klinik bulgularla kendini gösterebilir. Fakat bu bulguların tamamı hem malign hem de benign nedenlerden kaynaklanabilir. $\mathrm{Bu}$ durum jinekolog için benign malign ayırımında ve hastayı cerrahi değerlendirmeye yönlendirmede güçlüğe neden olmaktadır. Jakobs ve arkadaşlarının ${ }^{3}$ geliştirdiği RMI benign malign ayırımında güçlü bir araç olmuştur. RMI menopozal durum, kitlenin ultrasonografik görünümü, asit ve metastaz varlığı ile CA 12.5 değerinin kombine edilmesi ile elde edilmiştir ${ }^{3}$. RMI nin sınır değerinin 200 alınarak \%85 duyarlılık ve \%97 özgüllük ile 42 kat daha fazla malign olgular tahmin edilebildi ${ }^{3}$. Birçok çalışmada da sınır değerin 200 olması adneksiyal kitlenin benign malign ayırımında iyi bir duyarlılık ve özgüllüğe sahip olduğunu göstermiştir 3,11,12,13-17. Bu duyarlılık özellikle de postmenopozal hastalarda daha da belirgindir çünkü premenopozal dönemde endometriozis gibi birtakım klinik durumlar da skorun yüksek çlkmasına neden olabilir ${ }^{18,19}$. Bununla birlikte güncel kanıtlar optimal bir sınır değerinin belirlenmesinin zor olacağını göstermektedir ${ }^{20}$. Hatta bazı çalışmalarda belli toplumlarda RMI nin duyarlı olmadığı ve toplumlar için farklı sınır değerlerinin belirlenmesi amacıyla çalışmalara ihtiyaç olduğu bildirilmiştir ${ }^{21}$. Örneğin Tayland da yapılan çalışmalarda RMI sınır değerinin 200 alınmasının Avrupada yapılan çalışmalara göre daha az duyarlı olduğu görülmüştür ${ }^{22}$. Benzer şekilde Singapurdaki bir çalışma RMI 1, 2 ve 3 için duyarlılığın sadece $\% 12,5$ özgüllügün ise \%85 ile 90 arasında olduğunu göstermiştir ${ }^{23}$. Ancak bu çalışmada benign vakaların yaklaşık \%75'inin endometriotik kist olması önemli bir sınırlayıcı faktördü. $\mathrm{Bu}$ sonuçlar belli toplumlarda ilk zamanlarda önerilen sınır değerinin yeterli duyarlılık ve özgüllüğe sahip olmadığını göstermektedir. Ortadoğu ve Asyada yapılan çalışmalarda da sınır değerlerin daha farklı olduğu gösterilmiştir. Ashrafgangooei ve arkadaşları yaptıkları çalışmada 238 sınır değerinin, inceledikleri populasyon için en iyi sınır değer olduğunu göstermişlerdir ${ }^{21}$. Türkiye de yapılmış bir çalışmada ise sınır değerinin 250 alınması \%95,9 özgüllük \%75 duyarlılı̆̆a sahip olduğunu göstermiştir ${ }^{24}$. Özellikle de Türkiye de yapılmış çalışma başta olmak üzere diğer Asya çalışmaları bu çalışmaya benzer populasyonları içermeleri açısından daha değerlidirler. Ancak bizim çalışma sonuçlarımız diğerlerinin tersine en iyi performansın 100 sınır değeri alındığında ortaya çıktığını göstermiştir. Sınır değer 100 alındığında duyarlılık \%80 iken sınır değer 150 alındığında duyarlılık \%68 ve sınır değer 200 alındığında duyarlılık \%60 a düşmektedir. Yani veriler incelendiğinde RMI sınır değeri 100 olarak kabul edildiğinde 25 malign hastanın 5 tanesi saptanamazken, sınır değer 200 kabul edildiğinde 10 malign hasta gözden kaçacaktır. Diğer yayınlarla olan bu farkın nedenini belirlemek için RMİ değeri 100 ile 200 arasında 
olan 5 olgunun verilerini yeniden dönemde olan hastalardı. Genelleme yapmak değerlendirdik. Bu 5 olgunun 2'si germ hücreli için olgu sayısı yeterli olmasa da, bu bulgular tümör, 1'i metastatik, 1'i borderline müsinöz, 1'i müsinöz tümördü. Ayrıca gördük ki bu olguların Ca 125 değerleri ılımlı olarak yüksekti epitelyal seröz tipte olmayan over tümörlerini belirlemede RMİ'nin yeterince duyarlı olmadığı fikrini desteklemektedir. (aralık 35-54) ve 4 tanesi premenopozal

Tablo 3. Benign ve Malign Olguların Tanımlayıcı Özelliklerinin Değerlendirilmesi

\begin{tabular}{|c|c|c|c|c|}
\hline & & Benign ( $n=210)$ & Malign ( $\mathrm{n}=25$ ) & $p$ \\
\hline \multirow{2}{*}{ Yaş (yıl) } & Min-Mak (Medyan) & $16-88(45,5)$ & $23-86(47)$ & \multirow{2}{*}{$\mathrm{a} 0,42 \mathrm{C}$} \\
\hline & Ort \pm Ss & $45,2 \pm 14$ & $49,2 \pm 17,3$ & \\
\hline \multirow{2}{*}{ Kitle boyutu $(\mathrm{cm})$} & Min-Mak (Medyan) & $1-30(6)$ & $3-25(9)$ & \multirow{2}{*}{$\mathrm{a} 0,01$} \\
\hline & Ort $\pm S s$ & $6,9 \pm 3,9$ & $11 \pm 6,7$ & \\
\hline \multirow{2}{*}{ Ca 125} & Min-Mak (Medyan) & $3-4067(15,5)$ & $5-5172(48)$ & \multirow{2}{*}{$\mathrm{a} 0.001$} \\
\hline & Ort \pm Ss & $65,8 \pm 314,1$ & $520 \pm 1136,8$ & \\
\hline \multirow{2}{*}{ RMi } & Min-Mak (Medyan) & $3-12201(33)$ & $9-24201(405)$ & \multirow{2}{*}{$\mathrm{a} 0,001$} \\
\hline & Ort $\pm S s$ & $196,3 \pm 1051,2$ & $3592,8 \pm 6572,1$ & \\
\hline \multicolumn{2}{|c|}{ Menopozal durum n (\%) } & $83(39,5)$ & $12(48)$ & $\mathrm{b} 0,548$ \\
\hline Bilateralite & $\mathrm{n}(\%)$ & $33(15,7)$ & $7(28)$ & ${ }^{c} 0,155$ \\
\hline Multilokülasyon & $(\%)$ & $35(16,7)$ & $14(56)$ & $\mathrm{b}_{0,001}$ \\
\hline Solid alan & $\mathrm{n}(\%)$ & $25(11,9)$ & $19(76)$ & ${ }^{c} 0,001$ \\
\hline Asit & $\mathrm{n}(\%)$ & $1(0,5)$ & $7(28)$ & ${ }^{c} 0,001$ \\
\hline Metastaz & (\%) & $0(0)$ & $5(20,0)$ & $c^{c} 0,001$ \\
\hline
\end{tabular}

Tablo 4. Patoloji Sonucu ile RMİ Düzeyi (Kesme Değeri 100) İlişkisi

\begin{tabular}{lccccc}
\hline & \multicolumn{3}{c}{ Benign } & \multicolumn{3}{c}{ Malign } & \multirow{2}{*}{$p$} \\
\cline { 2 - 5 } & $\mathrm{n}$ & $\%$ & $\mathrm{n}$ & $\%$ & \\
\hline $\mathrm{RMI}<100$ & 171 & 81,4 & 5 & 20,0 & 0,001 \\
$\mathrm{RMI} \geq 100$ & 39 & 18,6 & 20 & 80,0 & \\
\hline $\mathrm{RMI}<150$ & 185 & 88,1 & 8 & 32,0 & 0,001 \\
$\mathrm{RMI} \geq 150$ & 25 & 11,9 & 17 & 68,0 & \\
\hline $\mathrm{RMI}<200$ & 189 & 90,0 & 10 & 40,0 & \multirow{2}{*}{0,001} \\
$\mathrm{RMI} \geq 200$ & 21 & 10,0 & 15 & 60,0 & \\
\hline Yates Contin & & & & &
\end{tabular}

Yates' Continuity Correction Test

Tablo 5. RMI ölçümlerine ilişkin tanı tarama testleri

\begin{tabular}{lccccc}
\hline & Kesme değeri & Duyarlılı & Özgüllük & Pozitif belirleyici değer & Negatif \\
\hline RMi & $\geq 100$ & 80,0 & 81,4 & 33,9 & 97,2 \\
\hline RMi & $\geq 150$ & 68,0 & 88,1 & 40,5 & 95,9 \\
\hline RMi & $\geq 200$ & 60,0 & 90,0 & 41,7 & 95,0 \\
\hline
\end{tabular}


Ayrıca çalışmamızın sonuçlarına göre, özellikle solid alan ve asit varlığının yüksek RMİ değeri ve malignite ile olan ilişkisi diğer malignite kriterlerine göre çok daha belirgindi.

Sonuç olarak çalışmamızda incelenen populasyon için adneksiyal kitlenin malign benign ayırımında en iyi RMI sınır değeri 100 olarak saptanmıştır. Ancak olguların özellikleri RMI kesme değerini önemli ölçüde etkileyebilmektedir. $\mathrm{Bu}$ nedenle RMI sinır değeri için global bir değerden söz etmek bu çalışma ve literatürdeki çalışma sonuçları ışığında olası değildir. $\mathrm{Bu}$ konuda değişik populasyonlarda daha fazla çalışmaya ihtiyaç olduğu görünmektedir.

Çıkar Çatışması Beyanı: Yazarlar çıkar çatışması olmadığını bildirmişlerdir.

Finansal Destek: $\mathrm{Bu}$ çalışma her hangi bir fon tarafından desteklenmemiştir.

Declaration of Conflicting Interests: The authors declare that they have no conflict of interest.

Financial Disclosure: No financial support was received.

\section{KAYNAKLAR}

1. Abdulrahman GO Jr, McKnight L, Lutchman Singh K. The risk of malignancy index (RMI) in women with adnexal masses in Wales. Taiwan J Obstet Gynecol 2014; 53:376-81.

2. Howlader N, Noone AM, Krapcho M, et al., editors. SEER cancer statistics review, 1975e2008. Bethesda, MD: National Cancer Institute; 2011 [accessed 10.09.2011]. Available from, http://seer. cancer.gov/statfacts/html/ovary.html\#survival.

3. Jacobs I, Oram D, Fairbanks J, Turner J, Frost C, Grudzinskas JG. A risk of malignancy index incorporating CA 125, ultrasound and menopausal status for the accurate preoperative diagnosis of ovarian cancer. Br J Obstet Gynaecol 1990; 97:922-9.

4. Buys SS, Partridge E, Black A, et al. Effect of screening on ovarian cancer mortality: the Prostate, Lung, Colorectal and Ovarian (PLCO) Cancer Screening Randomized Controlled Trial. JAMA 2011; 305: 2295303.

5. Buys SS, Partridge E, Greene $\mathrm{MH}$, et al. Ovarian cancer screening in the Prostate, Lung, Colorectal and Ovarian (PLCO) cancer screening trial: findings from the initial screen of a randomized trial. Am J Obstet Gynecol 2005;193: 1630-9.
6. van Nagell JR, DePriest PD, Ueland FR, et al. Ovarian cancer screening with annual transvaginal sonography: findings of 25,000 women screened. Cancer 2007; 109: 1887-96.

7. van Nagell JR, Miller RW, DeSimone CP, et al. Longterm survival of women with epithelial ovarian cancer detected by ultrasonographic screening. Obstet Gynecol 2011;118:1212-21.

8. Kobayashi H, Yamada Y, Sado T, et al. A randomized study of screening for ovarian cancer: a multicenter study in Japan. Int J Gynecol Cancer 2008;18:414-20.

9. Menon U, Gentry-Maharaj A, Hallett R, et al. Sensitivity and specificity of multimodal and ultrasound screening for ovarian cancer, and stage distribution of detected cancers: results of the prevalence screen of the UK Collaborative Trial of Ovarian Cancer Screening (UKCTOCS). Lancet Oncol 2009; 10:327-40.

10.Jacobs IJ, Menon U, Ryan A, et al. Ovarian cancer screening and mortality in the UK Collaborative Trial of Ovarian Cancer Screening (UKCTOCS): a randomised controlled trial. Lancet 2016;387:945-56.

11. Manegold-Brauer G, Buechel J, Knipprath-Mészaros A, et al. Improved Detection Rate of Ovarian Cancer Using a 2-Step Triage Model of the Risk of Malignancy Index and Expert Sonography in an Outpatient Screening Setting. Int J Gynecol Cancer 2016; 26: 1062-9

12. Tingulstad S, Hagen B, Skjeldestad FE, et al. Evaluation of a risk of malignancy index based on serum CA125, ultrasound findings and menopausal status in the pre-operative diagnosis of pelvic masses. Br J Obstet Gynaecol 1996; 103: 826-31.

13. Chia YN, Marsden DE, Robertson G, et al. Triage of ovarian masses. Aust N Z J Obstet Gynaecol 2008; 48: 322-8.

14.van den Akker PA, Aalders AL, Snijders MP, et al. Evaluation of the Risk of Malignancy Index in daily clinical management of adnexal masses. Gynecol Oncol 2010; 116: 384-8.

15. Morgante G, la Marca A, Ditto A, et al. Comparison of two malignancy risk indices based on serum CA125, ultrasound score and menopausal status in the diagnosis of ovarian masses. Br J Obstet Gynaecol 1999; 106: 524-7.

16. Davies AP, Jacobs I, Woolas R, et al. The adnexal mass: benign or malignant? Evaluation of a risk of malignancy index. Br J Obstet Gynaecol 1993; 100: 927-31.

17. Clarke SE, Grimshaw R, Rittenberg P, et al. Risk of malignancy index in the evaluation of patients with adnexal masses. J Obstet Gynaecol Can 2009;31:4405. 
18. Radosa MP, Vorwergk J, Fitzgerald J, et al. Sonographic discrimination between benign and malignant adnexal masses in premenopause. Ultraschall Med 2014; 35: 339-44.

19.van den Akker PA, Aalders AL, Snijders MP, et al. Evaluation of the Risk of Malignancy Index in daily clinical management of adnexal masses. Gynecol Oncol 2010; 116: 384-8.

20. Guideline Development Group. Clinical guideline e ovarian cancer: the recognition and initial management of ovarian cancer. London: National Institute for Health and Clinical Excellence; 2011 [accessed: 06.10.11]. Available from, http://www.nice.org.uk/nicemedia/live/13464/542 66/54266.pdf.
21. Ashrafgangooei T, Rezaeezadeh M. Risk of malignancy index in preoperative evaluation of pelvic masses. Asian Pac J Cancer Prev 2011; 12: 1727-30.

22. Moolthiya W, Yuenyao P. The risk of malignancy index (RMI) in diagnosis of ovarian malignancy. Asian Pac J Cancer Prev 2009; 10: 865-8.

23. Ong C, Biswas A, Choolani M, Low JJ. Comparison of risk of malignancy indices in evaluating ovarian masses in a Southeast Asian population. Singapore Med J 2013; 54: 136-9.

24.Yavuzcan A, Caglar M, Ozgu E, et al. Should cut-off values of the risk of malignancy index be changed for evaluation of adnexal masses in Asian and Pacific populations? Asian Pac J Cancer Prev 2013; 14: 54559. 